Tropical Journal of Pharmaceutical Research September 2021; 20 (9): 1811-1818

ISSN: $1596-5996$ (print); 1596-9827 (electronic)

(C) Pharmacotherapy Group, Faculty of Pharmacy, University of Benin, Benin City, 300001 Nigeria.

\title{
Protective effect of EGb761 against Aß1-42 -induced SH- SY5Y cells injury and blood-brain barrier disruption via regulating Akt/Nrf2 signaling pathway
}

\author{
Liling Wang ${ }^{1}$, Jianhua Mi ${ }^{1}$, Yeping Song ${ }^{1}$, Pengfei Wang ${ }^{2 *}$ \\ ${ }^{1}$ Department of Neurology, ${ }^{2}$ Department of Cardiology, South Campus of Renji Hospital Affiliated to Shanghai Jiao Tong \\ University School of Medicine, Shanghai 201112, China
}

*For correspondence: Email: hjv7856@126.com; Tel: +86-18290772017

Sent for review: 22 April 2020

Revised accepted: 29 May 2020

\begin{abstract}
Purpose: Alzheimer's disease $(A D)$ is a common disease in the world caused by deposition in the brain parenchyma, accumulation of beta amyloid which leads to the blood brain barrier (BBB) disruption. Regardless of enough progress in the treatment of $A D$, the principal mechanism of $B B B$ injury is yet not clear.

Methods: In this study we examined the impact of EGb761on Aß 1-42-induced SH-SY5Y cells in vitro model of $A D$. Cell viability was assessed by using MTT assay, flow cytometry was used to check the rate of cell apoptosis, ROS generation and BBB leakage was assessed by measuring the level of fluorescence in A $A$-induced $S H-S Y 5 Y$ cells using a reactive oxygen species kit assay and BBB permeability assay, and mRNA levels of Bax, Bcl-2, caspase-3 was measured by using RT-qPCR. Furthermore, western blot analysis was used to measure the protein expressions of Akt, Nrf2 and HO-1 in $A \beta$ 1-42-induced SH-SY5Y cells.

Results: The effect of EGb761 was investigated on the cell apoptosis induced by $A \beta$ 1-42 and generation of ROS and we found that EGb761 plays a protective role against cell injury induced by $A \beta$ 1-42. Cell apoptosis and ROS generation in SH-SY5Y cells decreased significantly with the treatment of EGb761. Furthermore, BBB permeability reduced considerably when the cells treated with EGb761 and the expression levels of Caspase-3 and Bax decreased while that of Bcl-2 were markedly increased in the A 3 1-42-induced SH-SY5Y cells. Also, an increased in expression levels of p-Akt, Nrf2 (nucleus) and HO-1 was observed with the treatment of EGb761 in A 1-42-induced SH-SY5Y cells.

Conclusion: It can be concluded from these results that EGb761 could play a protective role by inhibiting apoptosis and protect $A \beta$ 1-42-induced cell injury in vitro model of $A D$ via activating Akt/Nrf2 signaling pathway. Our study suggested that EGb761 might be a therapeutic agent for the prevention and treatment of $A D$.
\end{abstract}

Keywords: EGb761, oxidative stress, Alzheimer's disease (AD), BBB, Akt/Nrf2

This is an Open Access article that uses a funding model which does not charge readers or their institutions for access and distributed under the terms of the Creative Commons Attribution License (http://creativecommons.org/licenses/by/4.0) and the Budapest Open Access Initiative (http://www.budapestopenaccessinitiative.org/read), which permit unrestricted use, distribution, and reproduction in any medium, provided the original work is properly credited.

Tropical Journal of Pharmaceutical Research is indexed by Science Citation Index (SciSearch), Scopus, International Pharmaceutical Abstract, Chemical Abstracts, Embase, Index Copernicus, EBSCO, African Index Medicus, JournalSeek, Journal Citation Reports/Science Edition, Directory of Open Access Journals (DOAJ), African Journal Online, Bioline International, Open-J-Gate and Pharmacy Abstracts

\section{INTRODUCTION}

Alzheimer's disease $(A D)$ is a common neurodegenerative disease worldwide that leads to memory loss and behavioral deterioration [1]. An essential factor of the pathogenesis of $A D$ is the accumulation of amyloid-beta $(A \beta)$ [2]. Oxidative stress is the leading cause of cell 
death, and mostly cellular proteins are damaged because of the overproduction of reactive oxygen species (ROS). The oxidative stress plays a vital role in the stimulation of many neurodegenerative diseases such as Huntington's disease [3], Parkinson's disease [4] and $A D$ [5]. The blood brain barrier (BBB) is a physiological barrier which is formed by brain endothelial cells and joined together by numerous junctions [6]. BBB plays a vital role in controlling various molecules and then create a blockage through brain endothelium [7]. The accumulation of $A \beta$ is caused by the leakage of $\mathrm{BBB}$ due to cerebrovascular changes, leading to the progression of $A D$ [8]. Although great research has been done to study the pathogenesis of $A D$, however, the deposition of $A \beta$ in brain and cerebral capillaries is not clear. Moreover, the exact mechanism of BBB leakage is also unknown. Therefore, targeting $A \beta$-induced blood brain barrier disruption in SH-SY5Y cells might be a promising approach for the $A D$ treatment. Ginkgo biloba leaf extract are used as herbal medicine for many diseases because of its neuroprotective effect and cognitive impairment properties [9]. Flavonoids, bilobalide, ginkgolic acid and ginkgolides are the important compounds found in EGb761 extract [10]. $E G b 761$ has gained much attention because of its therapeutic effects in pharmacology, such as protection of microvascular endothelial cells and especially for the treatment of $A D$ [11]. Furthermore, there is evidence that EGb761 acted as a protective drug in $A D$ treatment $[12,13]$ by limiting neural and vascular damage [12]. However, the exact molecular mechanism essential for this treatment is still unclear. So there is a need to investigate the underlying mechanism by which EGb761 exerts its neuroprotective role in the treatment of AD.

Recently, nuclear factor erythroid 2-related factor 2 (Nrf2) has been reported to have crucial function against oxidative stress [14]. Nrf2 is a redox-regulated gene whose level is reduced in the nucleus during neuroinflammation diseases such as AD [14]. Anti-oxidative enzymes such as heme oxygenase-1 (HO-1) are produced during the activation of Nrf2 [15]. Besides, HO-1 induction inhibited the inflammation and oxidative stress signifying the effective function of Akt/Nrf2 in $A D$ [16]. Other studies have revealed that Akt activated expression of $\mathrm{HO}-1$ via the Nrf2 signaling pathway [17]. These studies suggested that Akt/Nrf2 is related to the inflammation and oxidative stress suggesting that Akt/Nrf2 might be a therapeutic target for $A D$. Therefore, the purpose of this present study was to investigate the effect of EGb761 on the activation of Akt/Nrf2 signaling pathway in $A \beta$-induced cellular model of $A D$. In this study, we demonstrated the protective effect of EGb761 on $A \beta$-induced BBB disorder in SH-SY5Y cells via Akt/Nrf2 signaling pathway.

\section{MATERIALS AND METHODS}

\section{Reagent preparation}

As described in previous studies, $A \beta$ 1-42 was prepared by using Lyophilized human $A \beta$ 1-42 [18]. $A \beta$ 1-42 was first dissolved in $1 \mathrm{mM}$ of hexafluoroisopropanol (HFIP; PARCHEM, New York, USA) and then into sterilized microcentrifuge tubes. This HFIP was then kept in Speed Vac, and the peptide was stored at a freezing temperature of $-20^{\circ} \mathrm{C}$. A $2 \mathrm{mM} A \beta \quad 1-42$ was first dissolved in DMSO (Sigma-Aldrich, St Louis, USA) followed by its dilution into frozen Opti-MEM (Thermo Fisher Scientific, New Jersey, USA). The solution was centrifuged for 5 minutes and incubated for $24 \mathrm{hr}$ at $4^{\circ} \mathrm{C}$. EGb761 was dissolved in DMSO $(150 \mathrm{mg} / \mathrm{ml})$ and kept at $25^{\circ} \mathrm{C}$. The concentrated stock solution was diluted with Opti-MEM to make the required concentrations $(25,50,100,250 \mu \mathrm{g} / \mathrm{ml})$ of EGb761.

\section{Cell culture}

SH-SY5Y cells (ATCC, Molsheim Cedex, France) were cultured in Dulbecco's modified Eagle's medium (DMEM; Biocompare, CA, USA) containing $20 \%$ FBS (Biological Industries, CT, USA), $100 \mu \mathrm{g} / \mathrm{ml}$ streptomycin and $1 \%$ penicillin (Cell Biogics, Chicago, USA). These cells were then kept in a humidified incubator which contains $95 \%$ air and $5 \% \quad \mathrm{CO}_{2}$ at $37^{\circ} \mathrm{C}$. The medium was replaced and renewed every 3 days.

\section{Cell transfection}

SH-SY5Y cells were raised to $80-90-\%$ confluence before treatment. Then these cells were washed with PBS twice and then the culture medium was replaced with Opti-MEM medium (Sigma-Aldrich, MO, USA). For the treatment of SH-SY5Y cells with EGb761 and $A \beta$ 1-42, these cells were pretreated with EGb761 for $1 \mathrm{~h}$ followed by the treatment with $A \beta$ 1-42.

\section{Cell viability}

MTT assay was used to measure cell viability. 96-well plates were used to seed SH-SY5Y cells and then these cells were treated with different concentrations of EGb761. MTT (Abcam, ON, Canada) reagent $(1 \times 50 \mathrm{ml})$ stock solution was diluted in PBS (Biocompare, CA, USA) and then 
added to each well containing $100 \mu \mathrm{L}$ of DMSO medium. The medium was removed and replaced after $3 \mathrm{hr}$ and $30 \mathrm{~min}$ of incubation and $37^{\circ} \mathrm{C}$, and these crystals were lysed with $100 \mu \mathrm{L}$ DMSO medium by moderately shaking the plate. A microplate reader (Abcam Inc., ON, Canada) was used to measure the absorbance at $590 \mathrm{~nm}$. The cell viability was measured as a percentage relative to the control cells.

\section{Flow cytometry}

Hoechst-33258 (Cyman, Michigan, USA) was used to check the cell apoptosis in SH-SY5Y cells. Plates (6-well) having density $1 \times 10^{5}$ cells/well were used to culture cells with DMEM for $24 \mathrm{hr}$ till it reached $95 \%$ confluence. The culture medium was replaced with DMEM without serum, and these cells were centrifuged for 10 min at room temperature. They were then washed at with PBS for almost $30 \mathrm{~min}$ at room temperature and then the apoptotic cells were suspended using an Annexin V-FITC (Biolegend, CA, USA) buffer. Cells were treated with $10 \mu \mathrm{L}$ of $\mathrm{PI}$ and $10 \mu \mathrm{L}$ of Annexin V-FITC and incubated in the dark for $30 \mathrm{~min}$ at room temperature. Finally apoptotic cells were observed on the basis of nuclear morphological changes by using a fluorescent microscope (Biocompare, MA, USA) at $\times 400$ magnification. The ratio of apoptotic cells to total cells was used to calculate the percentage of apoptotic cells. The process was repeated three times.

\section{ROS measurement}

A Reactive Oxygen Species Kit (Abcam, ON, Canada) was used to measure the level of cellular reactive oxygen species. In viable cells, $\mathrm{H} 2 \mathrm{DCFDA}$ is oxidized by reactive oxygen species to 2', 7' - dichlorofluorescein (DCF). This DCF is highly fluorescent compound at $535 \mathrm{~nm}$. Cells were rinsed with PBS three times and then with H2DCFDA. These cells were diluted to a final concentration of $10 \mu \mathrm{M}$ followed by the incubation in the dark for $40 \mathrm{~min}$ at $37^{\circ} \mathrm{C}$. A 96well plate were used to wash stained cells with PBS and then analyzed by using fluorescent microscopy (Abcam, ON, Canada). The fluorescence levels in the cells were measured by a microplate reader (Abcam, ON, Canada) with excitation at $485 \mathrm{~nm}$ and emission at 535 $\mathrm{nm}$. The cellular ROS level was expressed as a percentage of the control cells.

\section{BBB permeability}

An in vitro model of BBB co-culturing was established following the previous research [19]. An apical compartment on a polycarbonate membrane Transwell permeable insert (Thomas Scientific, NJ, USA) containing $6.5 \mathrm{~mm}$ diameter and $0.4 \mu \mathrm{m}$ pore size was used to culture $\mathrm{SH}$ SY5Y $\left(5 \times 10^{5}\right.$ cells $\left./ \mathrm{m}^{2}\right)$ cells. After cells reached $90 \%$ confluence, a $1.5 \mathrm{ml}$ of HHBS assay buffer (1.26 mM CaCl $2,0.49 \mathrm{mM} \mathrm{MgCl}, 5.33 \mathrm{mM} \mathrm{KCl}$, $0.44 \mathrm{mM} \mathrm{KH}_{2} \mathrm{PO}_{4}, 5.56 \mathrm{mM}$ glucose, $20 \mathrm{mM}$ HEPES, $\mathrm{pH}=7$ ) was added to the basolateral compartment. This culture medium was replaced with HHBS assay buffer $(0.5 \mathrm{ml})$. This medium was removed from the basolateral compartment after $30 \mathrm{~min}$ and a multiwall plate reader (BioRad, PA, USA) was used to measure the fluorescence in this medium at $490 \mathrm{~nm}$ excitation and $535 \mathrm{~nm}$ emission.

\section{RT-qPCR}

Total RNAs were extracted from the SH-SY5Y cells using the RNA Isolation Kit (Sigma-Aldrich, $\mathrm{MO}$, USA) according to the manufacturer's protocol. The concentration of RNA and purity were assessed by optical density spectrometry at $260 \mathrm{~nm}$. The total RNA of all samples was first reverse-transcribed into cDNA, followed by the amplification of PCR according to the manufacturer's instructions of the RT-PCR kit (Biocompare, CA, USA). Gene expression was detected with the following primers given in the Table 1. Results of RT-qPCR were calculated through $2^{-\triangle \Delta C t}$ methods to qualified expressions of RNAs.

Table 1: Primers used for detection of gene expression

\begin{tabular}{ll}
\hline Primers & Sequence \\
\hline BaxForward & GGCCTGAGTCCAGCTCTTTA \\
Bax Backward & GTCCTGGAGACAGGGACATC \\
Bcl-2 Forward & CCTCGCTGCACAAATACTCC \\
Bcl-2 Backward & TGGAGAGAATGTTGGCGTCT \\
Caspase-3 Forward & TCGGTCTGGTACAGATGTCG \\
Caspase-3 Backward & CTTCACCATGGCTCAGAAGC \\
$\beta$-actin Forward & CACCATGTACCCTGGCATTG \\
$\beta$-actin Backward & CCTGCTTGCTGATCCACATC \\
\hline
\end{tabular}

\section{Western blot analysis}

Cell extracts were prepared by rinsing the cells twice with PBS and suspended in RIPA lyse buffer (Biocompare, CA, USA) containing phosphatase inhibitors. The protein expressions of samples were examined by using bicinchoninin acid protein assay kit (SigmaAldrich, MO, USA). These proteins were loaded and subjected to $12 \%$ SDS-PAGE. The membranes were blocked with $5 \%$ skimmed milk for $2 \mathrm{hrs}$ at $25^{\circ} \mathrm{C}$ and incubated overnight at $4^{\circ} \mathrm{C}$. The primary antibodies used for incubation of these membranes are: anti-Bax (1:1000; NBP128566; Novous Biologicals, CO, USA ), anti-Bcl-2 
(1:1000; NB100-56098; Novous Biologicals, CO, USA), anti-Nrf2 (1:1000; NBP1-32822; Novous Biologicals, CO, USA), anti-HO-1 (1:1000; NBP197507; Novous Biologicals, CO, USA), anticaspase-3 (1:1000; NB100-56708; Novous Biologicals, CO, USA), anti-Akt (1:1000; NB10056749; Novous Biologicals, CO, USA) and anti$\beta$-actin (1:1000; NB600-501).

Peroxidase-conjugated anti-rabbit or anti-mouse (1:2000; NB100-305; Novous Biologicals, CO, USA) secondary antibodies were incubated for $1 \mathrm{~h}$ at room temperature. These membranes were depicted by using ECL western detection agent (Thermo Fisher Scientific, MA, USA). Proteins bands were visualized by a ChemiDoc ${ }^{\mathrm{TM}}$ MP Imaging System (170-01402; Bio-Rad, MA, USA).

\section{Statistical analysis}

All data were analyzed by IBM SPSS 18.0 software (IBM Inc., New York, USA) and expressed as the mean \pm SD and experiments were repeated three times. GraphPad Prism 7.0 (Graphpad Software, CA, USA) was used to perform statistical analysis. A student t-test or one-way analysis of variance (ANOVA) was used to find the significant difference in different groups. When the value of $p<0.05$, then it was considered statistically significant.

\section{RESULTS}

\section{EGb761 reduced $A \beta 1-42$-induced cell injury of SH-SY5Y cells}

MTT assay was used to check the effect of EGb761 on the cell viability of SH-SY5Y cells. From the results, it was clear that cell viability remained unchanged by the treatment with different concentrations of EGb761. While the cell viability considerably decreased when treated with EGb761 at a concentration of 250 $\mu \mathrm{g} / \mathrm{ml}$. (Figure 1) Consequently, the concentration of EGb761 between 50 and 100 $\mu \mathrm{g} / \mathrm{ml}$ was used for further experiments.

The SH-SY5Y cells were treated with different concentrations of EGb761 followed by the treatment with $A \beta$ 1-42. The results revealed that the cell viability decreased significantly when the $\mathrm{SH}-\mathrm{SY} 5 \mathrm{Y}$ cells treated with $A \beta \quad 1-42$ as compared to control group. On the other hand, treatment of SH-SY5Y cells with EGb761 considerably enhanced the cell viability in a concentration-dependent manner. (Figure 1).

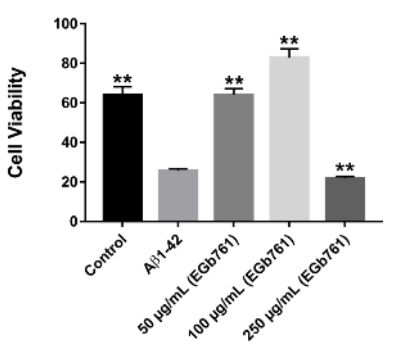

Figure 1: EGb761 reduced $A \beta 1-42$-induced cell injury of SH-SY5Y cells: MTT assay was used to measure the cell viability in A $\beta$-induced SH-SY5Y cells after treating with different concentrations of EGb761. P < 0.05

\section{EGb761 prevented A $\quad A$ 1-42-triggered apoptosis in SH-SY5Y cells}

The cells were incubated with EGb761 for 120 min and then treated with $A \beta$ 1-42 for almost one day to study the effect of EGb761 on the cell apoptosis in SH-SY5Y cells. We examined different concentrations of EGb761, and our results showed that the rate of cell apoptosis considerably increased when SH-SY5Y cells were treated with $A \beta$ 1-42 as compared to the control group. Moreover, if the cells were treated with EGb761 before treatment with $A \beta 1$ 1-42, then there was a decrease in the rate of cell apoptosis in SH-SY5Y cells. (Figure 2).

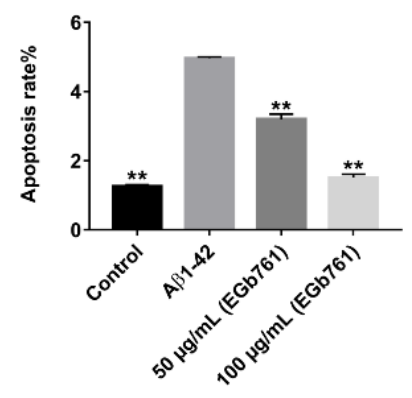

Figure 2: $E G b 761$ prevented $A \beta 1-42$-triggered apoptosis in SH-SY5Y cells: The rate of cell apoptosis in $\mathrm{A} \beta$-induced $\mathrm{SH}$-SY5Y cells was measured by using caspase- 3 assay. $P<0.05$

\section{EGb761 attenuated AB1-42-induced ROS generation in SH-SY5Y cells}

Oxidative stress is a crucial factor in producing cytotoxicity induced by $A \beta$ 1-42. Hence, Reactive Oxygen Species Kit was used to measure the level of cellular oxygen reactive species and check the effect of EGb761 on the generation of ROS in the cells induced by $A \beta$ 1-42. It can be seen from these results that there was a significant increase in the fluorescence level in SH-SY5Y cells signifying higher ROS generation

Trop J Pharm Res, September 2021; 20(9): 1814 
in the cells treated with $A \beta 1-42$ as compared to the control group. In contrast, the level of fluorescence in SH-SY5Y cells reduced when the cells were treated with EGb761 before the treatment with $A \beta$ 1-42 indicating that ROS generation decreased significantly in $A \beta$-induced SH-SY5Y cells. It can be concluded from these results that $E G b 761$ can significantly reduce the A 1 1-42-induced ROS generation in SH-SY5Y cells. (Figure 3).

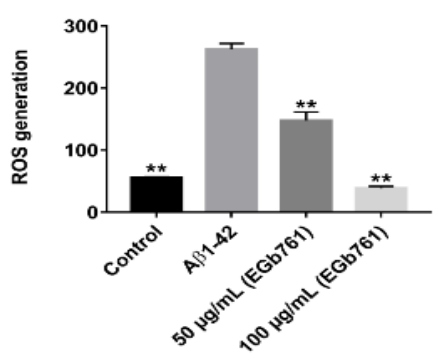

Figure 3: EGb761 attenuated $A \beta 1-42$-induced ROS generation in SH-SY5Y cells: A reactive oxygen species kit was used to determine the ROS generation in $\mathrm{A} \beta$-induced $\mathrm{SH}-\mathrm{SY} 5 \mathrm{Y}$ cells. $\mathrm{P}<0.05$

\section{EGb761 reduced $B B B$ leakage induced by the Aß1-42}

Previous research has shown that micro vascular injury was associated with leakage of BBB in AD patients [20]. Therefore, we used BBB permeability assay to check $B B B$ leakage in terms of fluorescence levels in $\mathrm{A} \beta$-induced $\mathrm{SH}$ SY5Y cells. Our results showed that fluorescence level in Aß-induced SH-SY5Y cells was higher indicating that barrier permeability increased in SH-SY5Y cells induced with $A \beta$ 142. While the treatment with EGb761 significantly reduced the fluorescence level in SH-SY5Y cells which in turn decreased the barrier permeability in the $A \beta$ 1-42-induced SH-SY5Y cells compared to the control group in a concentration-dependent manner. (Figure 4).

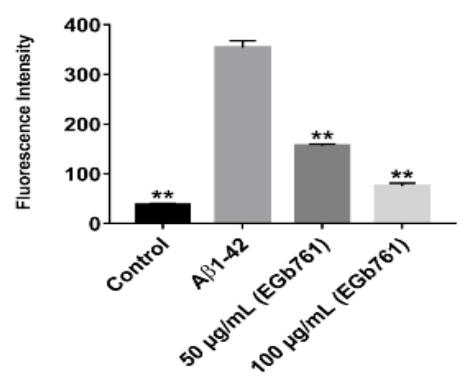

Figure 4: $E G b 761$ reduced $B B B$ leakage induced by the $A \beta 1-42$ : $B B B$ permeability was measured in $A \beta-$ induced $\mathrm{SH}-\mathrm{SY} 5 \mathrm{Y}$ cells by detecting the absorbance by using fluorescence spectrophotometry. $\mathrm{P}<0.05$
Effect of EGb761 on protein levels of Caspase-3, Bax and Bcl-2 in Aß1-42-induced SH-SY5Y cells

RT-qPCR was used to check the proteins expressions of Caspase- $3, \mathrm{Bax}, \mathrm{Bcl}-2$ in $\mathrm{A} \beta$ 142 -induced cells. From the results, it can be seen that the level of proteins expressions of Caspase- 3 and Bax significantly increased. In contrast, the expression of $\mathrm{Bcl}-2$ decreased significantly in $A \beta$ 1-42-induced SH-SY5Y cells compared to control group. (Figure 5) Furthermore, treatment with EGb761significantly reduced the proteins expressions of Caspase-3 and Bax while enhanced the level of proteins expressions of $\mathrm{Bcl}-2$ in $A \beta$ 1-42-induced $\mathrm{SH}$ SY5Y cells in a concentration-dependent manner. (Figure 5).

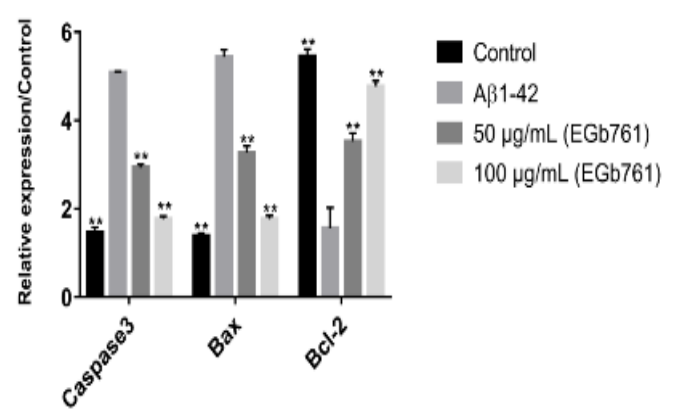

Figure 5: Effect of EGb761 on protein levels of Caspase-3, Bax and $\mathrm{Bcl}-2$ in $\mathrm{A} \beta 1-42$-induced $\mathrm{SH}$ SY5Y cells: RT-qPCR was used to measure the expression levels of caspase-3, Bax and $\mathrm{Bcl}-2$ in $A \beta-$ induced SH-SY5Y cells. $\mathrm{P}<0.05$

\section{EGb761 reversed $A \beta 1-42$-induced upregula- tion of p-Akt, nuclear Nrf2 and HO-1 expression in SH-SY5Y cells}

The proteins expressions of Akt/Nrf2/HO-1 signaling pathways were detected to examine the effect of EGb761 in SH-SY5Y cells by using western blot analysis. Results revealed that there was no difference in the proteins expressions of Nrf2 and total Akt proteins in the control group as well as in $A \beta$ 1-42-induced cells group. The proteins expressions of $p$-Akt, nuclear Nrf2 and HO-1 decreased significantly in A $\beta$ 1-42-induced cells as compared to the control group. However, treatment with EGb761 considerably increased the proteins expressions of p-Akt, nuclear Nrf2 and $\mathrm{HO}-1$. It can be concluded from these results that EGb761 could protect $A \beta$ 1-42-induced injury in SH-SY5y cells via activating Akt/Nrf2 signaling pathway (Figure 6).

Trop J Pharm Res, September 2021; 20(9): 1815 


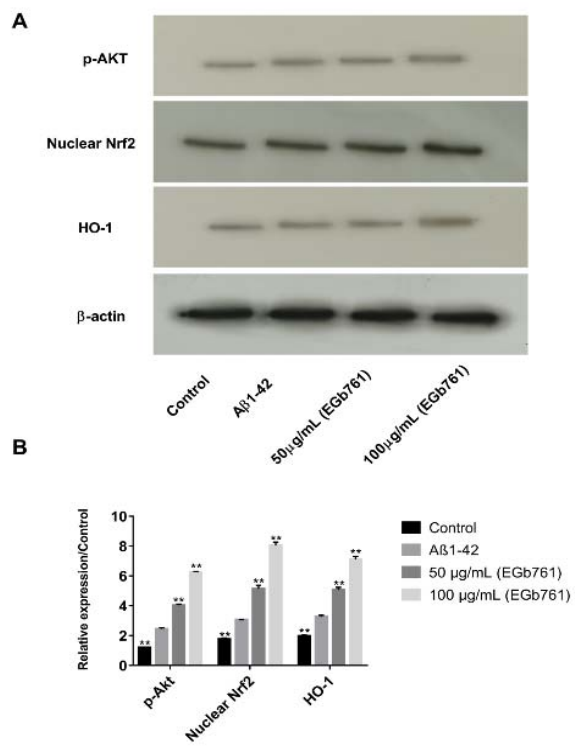

Figure 6: $E G b 761$ reversed $A \beta 1-42$-induced upregulation of HO-1 expression in SH-SY5Y cells: AB) Western blot analysis was used to measure the protein expressions of Akt/Nrf2 signaling pathway in $A \beta$-induced SH-SY5Y cells. $P<0.05$

\section{DISCUSSION}

The present study revealed the neuroprotective effects of EGb761 against A 3 -induced SH-SY5Y cells injury and blood brain barrier disruption in vitro model of AD. Previous research demonstrated that inflammation, ROS and oxidative stress are the critical factors for the progression of $A D$. Also, the deposition of $A \beta$ enhanced oxidative stress and ROS production, which leads to memory impairment and neurodegeneration diseases including AD [21]. Although the exact Pathogenic mechanism of BBB leakage is not clear. However, it has been proved from various animal models that $A \beta$ deposition in vessels leads to the disruption of the BBB [22]. In the present study we cultured $S H-S Y 5 Y$ cells with $A \beta$ to make a BBB model in $A D$ and determined the protective effect of EGb761 on this cell model of BBB. The cell viability of SH-SY5Y cells first decreased when these cells were induced with $A \beta$ while the rate of cell apoptosis increased in $\mathrm{A} \beta$-induced $\mathrm{SH}$ SY5Y cells. Also, there was an increase in ROS generation in A $\mathrm{A}$-induced $\mathrm{SH}-\mathrm{SY} 5 \mathrm{Y}$ cells. On the other hand, Treatment with EGb761 significantly increased cell viability and decreased the rate of cell apoptosis and the production of ROS in A $\beta$ induced SH-SY5Y cells.

EGb761 has been extensively used for the treatment of many neurodegenerative diseases, such as impaired cognition function in AD [23].
Previous research revealed that activation of caspase-3 could stimulate apoptosis in neurons by $A \beta$-induced inflammation injury while treatment with EGb761 and $\mathrm{HBO}$ reversed the effect of apoptosis [24]. Also, the treatment with EGb761 significantly enhanced the protein expressions of $\mathrm{Bcl}-2$ while decreased the activation of caspase-3. These findings suggested that EGb761 could improve antiapoptotic protein expressions by reducing the apoptosis of neurons induced by oxidative stress [25]. In the animal model of $A D$, the apoptosis was regulated by decreasing the expression of anti-apoptotic proteins and increasing the expressions of pro-apoptotic proteins, suggesting that the ratio of $\mathrm{Bax} / \mathrm{Bcl}-2$ is vital in neuronal apoptotic index [26]. Furthermore, Bcl-2 also plays a critical role in the regulation of cell death caused by oxidative stress [27]. Therefore, in this study we investigated the role of these antiapoptotic and pro-apoptotic proteins on a cellular model of $A D$. Our results indicated that proteins expressions of $\mathrm{Bcl}-2$ were significantly increased in $\mathrm{A} \beta$-induced $\mathrm{SH}-\mathrm{SY} 5 \mathrm{Y}$ cells when treated with $E G b 761$, while protein expressions of Bax and caspase-3 markedly decreased. These results indicated that treatment with EGb761 decreased the Bax and caspase- 3 protein expressions while increased $\mathrm{Bcl}-2$ proteins expressions, thus inhibited cell apoptosis in A $\beta$-induced $\mathrm{SH}$-SY5Y cells.

Nrf2 signaling pathways, are considered as antioxidant stress pathway, and played a vital role in response to oxidative stress [28]. In oxidative stress, the downstream antioxidant gene and activation of Nrf2 was controlled by PI3K/Akt signaling pathways [29]. Previous studies have demonstrated that Nrf2 could activate antioxidative enzymes such as HO-1 and NAPDH and can protect against oxidative stress in various neuroinflammation diseases such as ischemia. Also, the level of ROS and oxidative stress is increased by Nrf2 in a mice model of stroke disease [30]. The activation of anti-oxidant gene such as Nrf2 and HO-1 might be involved in the neuroprotective mechanism in vivo and vitro model of $A D$ [31]. In the present study the protein expressions of Nrf2, Akt and HO-1 was assessed to find the mechanism of EGb761 to protect $A \beta$ induced injury in SH-SY5Y cells. Our results showed that the protein expressions of p-Akt, nuclear Nrf2 and $\mathrm{HO}-1$ reduced in $\mathrm{A} \beta$-induced SH-SY5Y cells while treatment with EGb761 significantly enhanced the protein expressions of these signaling pathways. Also, EGb761 activated p-Akt followed by the upregulation of $\mathrm{HO}-1$ expression, which in return protected $\mathrm{A} \beta-$ induced injury in SH-SY5Y cells. 


\section{CONCLUSION}

EGb761 efficiently prevented $A \beta$-induced cell injury in SH-SY5Y cells by increasing cell viability and decreasing cell apoptosis and ROS generation. Moreover, EGb761 had a protective effect on reduction of BBB leakage. Furthermore, the protein expressions of Bax and caspase-3 significantly decreased while the expression level of $\mathrm{Bcl}-2$ increased in the cells treated with EGb761. Also, the expressions of $\mathrm{HO}-1$ were upregulated by the treatment with EGb761 via activation of Akt/Nrf2 pathway leading to the reduction in inflammatory injury induced by $A \beta$ in SH-SY5Y cells. These results suggested that EGb761 might be a therapeutic drug for the treatment of $A D$.

\section{DECLARATIONS}

\section{Funding}

Shanghai Jiao Tong University Medical School Affiliated to Renji Hospital South Hospital National Nature Cultivation Project (no. 2017PYQA01).

\section{Conflict of interest}

No conflict of interest is associated with this work.

\section{Contribution of authors}

We declare that this work was done by the authors named in this article and all liabilities pertaining to claims relating to the content of this article will be borne by the authors. Liling Wang and Jianhua Mi contributed equally to the study.

\section{Open Access}

This is an Open Access article that uses a funding model which does not charge readers or their institutions for access and distributed under the terms of the Creative Commons Attribution License (http://creativecommons.org/licenses/by/ 4.0) and the Budapest Open Access Initiative (http://www.budapestopenaccessinitiative.org/rea d), which permit unrestricted use, distribution, and reproduction in any medium, provided the original work is properly credited.

\section{REFERENCES}

1. Perrone L, Sbai O, Nawroth PP, Bierhaus A. The Complexity of Sporadic Alzheimer's Disease Pathogenesis: The Role of RAGE as Therapeutic Target to Promote Neuroprotection by Inhibiting Neurovascular Dysfunction. International journal of Alzheimer's disease. 2012; 2012:734956.

2. Meyer-Luehmann M, Spires-Jones TL, Prada C, GarciaAlloza $M$, de Calignon $A$, Rozkalne $A$, et al. Rapid appearance and local toxicity of amyloid-beta plaques in a mouse model of Alzheimer's disease. Nature. 2008;451(7179):720-4.

3. Machiela E, Dues DJ, Senchuk MM, Van Raamsdonk $J M$. Oxidative stress is increased in C. elegans models of Huntington's disease but does not contribute to polyglutamine toxicity phenotypes. Neurobiology of disease. 2016; 96:1-11.

4. Pan PK, Qiao LY, Wen XN. Safranal prevents rotenoneinduced oxidative stress and apoptosis in an in vitro model of Parkinson's disease through regulating Keap1/Nrf2 signaling pathway. Cellular and molecular biology (Noisy-le-Grand, France). 2016;62(14):11-7.

5. Garcia-Blanco A, Baquero M, Vento M, Gil E, Bataller L, Chafer-Pericas C. Potential oxidative stress biomarkers of mild cognitive impairment due to Alzheimer disease. Journal of the neurological sciences. 2017; 373:295302.

6. Abbott NJ, Patabendige AA, Dolman DE, Yusof SR, Begley DJ. Structure and function of the blood-brain barrier. Neurobiology of disease. 2010;37(1):13-25.

7. Yamada $M$, Naiki $H$. Cerebral amyloid angiopathy. Progress in molecular biology and translational science. 2012; 107:41-78.

8. Biron KE, Dickstein DL, Gopaul R, Jefferies WA. Amyloid triggers extensive cerebral angiogenesis causing blood brain barrier permeability and hypervascularity in Alzheimer's disease. PloS one. 2011;6(8): e23789.

9. Zhang $C$, Ren $C$, Chen $H$, Geng $R$, Fan $H$, Zhao $H$, et al. The analog of Ginkgo biloba extract 761 is a protective factor of cognitive impairment induced by chronic fluorosis. Biological trace element research. 2013;153(13):229-36.

10. Muller WE, Heiser J, Leuner $K$. Effects of the standardized Ginkgo biloba extract EGb 761(R) on neuroplasticity. International psychogeriatrics. 2012;24 Suppl 1: S21-4.

11. Jahanshahi M, Nikmahzar E, Yadollahi N, Ramazani K. Protective effects of Ginkgo biloba extract (EGB 761) on astrocytes of rat hippocampus after exposure with scopolamine. Anatomy \& cell biology. 2012;45(2):92-6.

12. Mashayekh A, Pham DL, Yousem DM, Dizon M, Barker $P B$, Lin DD. Effects of Ginkgo biloba on cerebral blood flow assessed by quantitative MR perfusion imaging: a pilot study. Neuroradiology. 2011;53(3):185-91.

13. Bastianetto S, Zheng WH, Quirion R. The Ginkgo biloba extract (EGb 761) protects and rescues hippocampal cells against nitric oxide-induced toxicity: involvement of its flavonoid constituents and protein kinase C. Journal of neurochemistry. 2000;74(6):2268-77.

14. Niedzielska E, Smaga I, Gawlik M, Moniczewski A, Stankowicz $P$, Pera J, et al. Oxidative Stress in 
Neurodegenerative Diseases. Molecular neurobiology. 2016;53(6):4094-125.

15. Alam J, Stewart D, Touchard C, Boinapally S, Choi AM, Cook JL. Nrf2, a Cap'n'Collar transcription factor, regulates induction of the heme oxygenase-1 gene. The Journal of biological chemistry. 1999;274(37):26071-8.

16. Farr SA, Ripley JL, Sultana R, Zhang Z, Niehoff ML, Platt $T L$, et al. Antisense oligonucleotide against GSK-3beta in brain of SAMP8 mice improves learning and memory and decreases oxidative stress: Involvement of transcription factor Nrf2 and implications for Alzheimer disease. Free radical biology \& medicine. 2014; 67:38795.

17. Huang CS, Lin AH, Yang TC, Liu KL, Chen HW, Lii CK. Shikonin inhibits oxidized LDL-induced monocyte adhesion by suppressing NFkappaB activation via upregulation of PI3K/Akt/Nrf2-dependent antioxidation in EA.hy926 endothelial cells. Biochemical pharmacology. 2015;93(3):352-61.

18. Li B, Zhong L, Yang $X$, Andersson T, Huang M, Tang SJ. WNT5A signaling contributes to $A$ beta-induced neuroinflammation and neurotoxicity. Plos one. 2011;6(8): e22920.

19. Liu W, Cai H, Lin M, Zhu L, Gao L, Zhong R, et al. MicroRNA-107 prevents amyloid-beta induced bloodbrain barrier disruption and endothelial cell dysfunction by targeting Endophilin-1. Experimental cell research. 2016;343(2):248-57.

20. Zipser BD, Johanson CE, Gonzalez L, Berzin TM, Tavares R, Hulette CM, et al. Microvascular injury and blood-brain barrier leakage in Alzheimer's disease. Neurobiology of aging. 2007;28(7):977-86.

21. Sultana $R$, Butterfield DA. Oxidative modification of brain proteins in Alzheimer's disease: perspective on future studies based on results of redox proteomics studies. Journal of Alzheimer's disease: JAD. 2013;33 Suppl 1: S243-51.

22. Kook SY, Hong HS, Moon M, Ha CM, Chang S, MookJung I. A beta(1)(-)(4)(2)-RAGE interaction disrupts tight junctions of the blood-brain barrier via $\mathrm{Ca}(2)(+)$ calcineurin signaling. The Journal of neuroscience: the official journal of the Society for Neuroscience. 2012;32(26):8845-54.
23. Evans JR. Ginkgo biloba extract for age-related macular degeneration. The Cochrane database of systematic reviews. 2013(1): Cd001775.

24. Calvert JW, Zhou C, Nanda A, Zhang JH. Effect of hyperbaric oxygen on apoptosis in neonatal hypoxiaischemia rat model. Journal of applied physiology (Bethesda, Md: 1985). 2003;95(5):2072-80.

25. Palzur E, Zaaroor M, Vlodavsky E, Milman F, Soustiel JF. Neuroprotective effect of hyperbaric oxygen therapy in brain injury is mediated by preservation of mitochondrial membrane properties. Brain research. 2008; 1221:12633.

26. Merry DE, Korsmeyer SJ. Bcl-2 gene family in the nervous system. Annual review of neuroscience. 1997; 20:245-67.

27. Bruce-Keller AJ, Begley JG, Fu W, Butterfield DA, Bredesen DE, Hutchins JB, et al. Bcl-2 protects isolated plasma and mitochondrial membranes against lipid peroxidation induced by hydrogen peroxide and amyloid beta-peptide. Journal of neurochemistry. 1998;70(1):319.

28. Zhang Y, Peng L, Yu X. [Protective effect of hydrogen sulfide on rats with myocardial ischemia/reperfusion injury and its mechanism]. Xi bao yu fen zi mian yi xue za zhi = Chinese journal of cellular and molecular immunology. 2015;31(3):316-20.

29. Yin $X$, Wang $X$, Fan Z, Peng $C$, Ren Z, Huang $L$, et al. Hyperbaric Oxygen Preconditioning Attenuates Myocardium Ischemia-Reperfusion Injury Through Upregulation of Heme Oxygenase 1 Expression: PI3K/Akt/Nrf2 Pathway Involved. Journal of cardiovascular pharmacology and therapeutics. 2015;20(4):428-38.

30. Jiang S, Deng C, Lv J, Fan C, Hu W, Di S, et al. Nrf2 Weaves an Elaborate Network of Neuroprotection Against Stroke. Molecular neurobiology. 2017;54(2):1440-55.

31. Godoy JA, Lindsay CB, Quintanilla RA, Carvajal FJ, Cerpa W, Inestrosa NC. Quercetin Exerts Differential Neuroprotective Effects Against $\mathrm{H} 2 \mathrm{O} 2$ and Abeta Aggregates in Hippocampal Neurons: the Role of Mitochondria. Molecular neurobiology. 2017;54(9):711628. 